\title{
Perspectives of Compulsory Secondary Education Students on Bilingual Sections in Madrid (Spain)
}

\author{
Zahra Chaieberras $^{1} \&$ Diego Rascón-Moreno ${ }^{2}$ \\ ${ }^{1}$ PhD student, Madrid, Spain. E-mail: fatimachaieb2012@hotmail.com \\ ${ }^{2}$ Departamento de Filología Inglesa, Facultad de Humanidades y Ciencias de la Educación, Universidad de Jaén, \\ Jaén, Spain \\ Correspondence: Diego Rascón-Moreno, Departamento de Filología Inglesa, Facultad de Humanidades y \\ Ciencias de la Educación, Edificio D-2, Universidad de Jaén, Jaén, 23071, Spain. Tel: 34-953-21-2609. E-mail: \\ drascon@ujaen.es
}

Received: May 10, 2018 Accepted: September 26, 2018 Online Published: September 29, 2018

doi: 10.5539/elt.v11n10p152 URL: http://doi.org/10.5539/elt.v11n10p152

\begin{abstract}
This article presents an empirical study about the students' perspectives on bilingual sections in Compulsory Secondary Education (CSE) in the Community of Madrid, Spain. Its aim is to highlight the students' opinions and their level of satisfaction of Content and Language Integrated Learning (CLIL) in this monolingual setting. The results extrapolate from the analysis of questionnaires and focus groups interviews. These two methods of research gave excellent opportunities for 754 bilingual participants in 18 bilingual schools (schools are public, charter, and private ones from both rural and urban areas) to expose their opinions and attitudes about the program. Thus, the article outlines the main findings in relation to the following factors: students' use, competence and development of English in class; methodology; materials and resources; evaluation; teachers' use, competence and development of English in class; mobility; improvement and motivation towards learning English; teacher training and mobility; and finally, overall appraisal of bilingual sections.
\end{abstract}

Keywords: CLIL, compulsory secondary education, interviews, Madrid region, questionnaires, students' perspectives

\section{Introduction}

In recent years, there has been an increasing interest in language learning, simply because "the role of language in a society is built into its structures to such a degree that it is a fundamental variable in that society" (González, 2008, p. 293). Educational models have begun to change shape and make a shift from the traditional model of education to a modern one. As Hufeisen (2007, p. 120) has stated, "It has been established that the traditional second language acquisition models no longer suffice to describe and explain the complex acquisition process of foreign languages."

Content and Language Integrated Learning (CLIL) is "a dual-focused educational approach in which an additional language is used for the learning and teaching of content and language" (Coyle, Hood, \& Marsh, 2010, p. 1). It has been introduced into the educational systems throughout the world, even though "the idea of teaching subject matters through more than one language is not new" (Lorenzo, Casal, \& Moore, 2009, p. 418). It has developed into an innovative way for education to respond to the challenges of globalization and to society's demands for interculturality and intercommunication.

CLIL developed from immersion education in Canada and bilingual approaches and methodologies in the United States; and, it is regarded as the European approach to bilingual education, being widespread throughout the continent. This claim is supported by Brevik and Moe (2012), who stated that "CLIL is the European counterpart of the Canadian immersion programs" (p. 215). Coyle (2012) defined CLIL as a methodology that "is a developing, flexible concept where content and foreign languages are integrated in some kind of mutually beneficial way to ensure that there are 'value added' experiences to educational outcomes for a wide range of students" (p. 28).

For example, the demand for bilingualism and trilingualism throughout the Spanish educational system has become strong and the diversity of linguistic variation has become increasingly broader. Durán-Martínez and 
Beltrán-Llavador (2016) acknowledged that "after the British Council/MEC (Ministry of Education and Culture, our own development of the term) agreement, most autonomous communities in Spain started to regulate bilingual education, spreading the model throughout the country" (p. 80). Immersion programs and, in particular, CLIL have become the most popular language acquisition programs within the educational system. In a very short time, English language has taken on an important role as a language of instruction in both monolingual and bilingual schools and universities in Spain.

Concerning Spain, Fernández Fontecha (2009) stated that "mirroring the European language policy, Content and Language Integrated Learning (CLIL) or bilingual education is nowadays receiving increasing attention in Spanish education" (p. 3). Coyle (2010) documented, "Spain is rapidly becoming one of the European leaders in CLIL practice and research" (p. viii). The growth of using English as an additional language in every region of Spain, the increase of bilingual schools in both monolingual and bilingual regions, and the gradually increasing enrollment of students into those schools should be recognized. Pérez Cañado (2011) has underscored this notion by indicating that this new lingua franca has taken center stage,

In both bilingual communities where English is a third language taught through CLIL (The Basque Country, Catalonia, Valencia, the Balearic Islands, Galicia) and in monolingual communities conspicuous for their lack of tradition in foreign language teaching (e.g. Extremadura, Castilla-La Mancha, or Andalusia (p. 392).

Consequently, Spain has been challenged with adopting a new approach to learning a foreign language (FL), not only as a policy change in monolingual or bilingual regions, but also as a way to enhance education and advance the welfare of its citizens. This is so because it is apparent that "mastering English, no doubt, has innumerable advantages to students, educators, civil servants, and professionals worldwide, irrespective of ethnic background or nationality" (Obiakor, Bakken, \& Rotatori, 2010, p. 59).

Today's educational environment in Spain and especially in Madrid is characterized by the increasing use of a FL (English in the majority of cases) to implement a bilingual education in schools and institutions as mandated by Orden 1317/2015, de 7 mayo, de la Consejería de Educación, Juventud y Deporte. Fernández and Halbach (2011) also stated that:

In March 2004 the regional government of Madrid issued a decree through which it set up a bilingual project to be implemented gradually in primary education, starting with the first year of primary and moving upwards to eventually cover the six years of primary education (p. 241).

This increased use of a FL is a result from the need to communicate in another language, and also from the recognition of communicating in English as a means to economic independence. Bruton (2013, p. 588) claimed that "what makes CLIL so attractive in current L2 pedagogy is that the content is expected to give the use of the foreign language (FL) a communicative purpose." Furthermore, the new bilingualism and bilingual programs have been seen as an innovative and "effective way to provide students with linguistic skills in an additional language (mainly English) that are absolutely essential in today's job market" (Pavón Vázquez \& Gaustad, 2013, p. 84). Thus, the Spanish government has worked hard to innovate teaching and learning methodology by introducing an additional language. In consequence, both bilingual and monolingual autonomous communities in the country have been adopting English into their respective educational systems.

It is worth noting that Spain faces two separate challenges related to language policy and language learning. Some regions have two official languages, and English is taught as a third language, such as "Galician (Gallego), Catalán, the language of Barcelona and some nearby regions (e.g., Majorca and Valencia), and Basque (a linguistic isolate, apparently unrelated to any other European language)" (Field, 2011, p. 2). Those regions reap the benefits of having a language policy that incorporates their bilingual programs with two co-official languages. This bilingualism is advantageous for the success of CLIL; as Ruiz de Zarobe and Lasagabaster (2010) have acknowledged, "in bilingual communities CLIL has evolved as the best approach to incorporate foreign languages in a system where already two languages need to be accommodated in the curriculum" (p. x).

Conversely, other communities are monolingual, such as Andalusia, Extremadura, and Madrid. They have only one language: Spanish. Today, however the Spanish Ministry of Education has encouraged all monolingual communities to integrate a foreign language into their educational institutions. According to Lorenzo, Casal, Quiñones, and Moore (2007), "the Plan de Fomento del Plurilinguismo in Andalusia and the Bilingual network in the Comunidad de Madrid encompass meaningful instances of the emergence of foreign languages as vehicles of instruction in state education" (p. 12).

Besides, teachers are compelled to create an effective learning environment with greater exposure to English in which the learners must perform in that language, whether it is their L2 or L3. Not only should the time devoted 
to language increase, but also the quality of teaching practice improve (see Ruiz Goméz, 2015, p.14).

\subsection{Bilingual Projects in Madrid}

Two different bilingual education initiatives have been implemented in the region of Madrid in the last three decades. As Relaño Pastor (2014, p. 132) has put it,

The first one, known as the MEC/British Council Project, was signed in 1996 by the Spanish Ministry of Education and The British Council, and the second one, known as the Comunidad Autónoma de Madrid (CAM) Bilingual Project, was put into effect by the local administration of the Madrid Region in 2004.

The CAM bilingual project "works with two modalities of bilingual education: The Bilingual Programme and the Bilingual Section" (Vázquez, 2015, p. 145). All bilingual schools in Madrid offer both modalities. Regarding the Bilingual Program (programa bilingüe), students learn English both as a subject and through other content areas taught in this language. They have to learn at least one non-compulsory subject in English, such as Art, Music, or Physical Education. Schools can choose which one.

Under the Bilingual Section (Sección Bilingüe), students have to learn additional compulsory disciplines in English, such as Science, Geography and History. Moreover, each day students take one hour of advanced English in order to expand their linguistic level, as well as their academic performance. Overall, there is much more time devoted to teaching and learning in English in bilingual sections than in bilingual programs.

Moreover, the demand by students and families to enroll in this type of bilingual education is increasing. The Bilingual Section students have a moderately advanced level of English. In general, Bilingual Sections are small, made up of between fifteen and twenty students. They are taught most of their subjects in English, except for Spanish Language and Math, which must be given in Spanish.

In Bilingual Sections the teachers are bilingual and there is a native English conversation instructor. Natural and Social Sciences are the main subjects that each bilingual school is required to teach via English. Art and Physical Education are optional subjects that can also be taught in English.

It is also important to point out that all schools are compelled to follow the Orden 1317/2015, de 7 mayo, de la Consejería de Educación, Juventud y Deporte. The schools are required to base their bilingual programs on prescribed, fundamental criteria. The order mandates that each school teaches five hours of English per week, and students should receive $30 \%$ of the academic course in English. Within the same line, Fernández and Halbach (2011) have explained,

To implement the project, the number of teaching hours for English was extended from three to five, and schools were required to teach at least $30 \%$ of their teaching hours through the medium of English. Any subject could be chosen for this, except for Mathematics and Spanish language (p. 241).

\subsection{Bilingual Project Goals}

Although the decision to implement bilingual education in the Comunidad de Madrid (CAM) is aiding students in becoming bilingual in Spanish and English, "the target is to prepare the students in the Comunidad de Madrid to become fully competent in English" (Gerena \& Verdugo, 2014, p. 121). Students need to reach a high level of proficiency to meet the challenges and demands of the future. Offering a practical method to learn the languages through bilingual education also, without doubt, fosters cultural awareness and supports cognitive skills. The rise of English as a second language in Madrid's schools serves the educational need of most of the students to communicate and to participate as global citizens, while also learning academic content.

Furthermore, because of the strong interest in modernization and globalization, the necessity for cultural and diversity awareness through school is essential, locally, regionally, and globally. Lessons about culture have been introduced as techniques to reinforce effective and fluid communication skills. An important aim of that project has been to encourage both teachers and students to participate in exchange programs outside of Spain and to promote opportunities to contact and to interact with native speakers, allowing for Spaniards to experience a real integration into other societies and to gain a deeper understanding of cultural differences and similarities.

\subsection{Objectives}

The main objective of this study is to present a comprehensive evaluation of how CLIL is working in a monolingual context. It determines qualitatively the amount of the students' satisfaction generated by CLIL programs. Specifically, the goal is to extensively examine CSE student perspectives on bilingual sections in Madrid in consideration of students' use, competence and development of English in class; methodology; materials and resources; evaluation; teachers' use, competence and development of English in class; mobility; improvement and motivation towards learning English; teacher training and mobility; motivation and workload; 
and finally, overall appraisal.

\section{Method}

\subsection{Instruments}

The instruments of the sample are two instruments designed by Pérez Cañado as a part of research project entitled: The effects of Content and Language Integrated Learning in monolingual communities: A large-scale evaluation; Proyectos de Investigación de Excelencia de la Junta de Andalucía, funded and supported by the Spanish Ministry of Economy and Competitiveness.

The survey questionnaire contains 49 items built on seven important thematic blocks. These thematic blocks examine and evaluate the following factors: students' use, competence and development of English in class; methodology; materials and resources; evaluation; teachers' use, competence and development of English in class; mobility; and finally, improvement and motivation towards learning English. It is available online (see Pérez Cañado, 2016, pp. 101-106)

The interview protocol was structured using ten thematic blocks with the aim of examining again the seven broad areas in the questionnaires mentioned above. Furthermore, an overall appraisal of the bilingual program could be made at the end. The purpose of the interview was to give students the chance of expanding on the issues about which they had just been surveyed. Thus, information obtained from interviews complemented the data collected through questionnaires and allow drawing a complete picture of how CLIL is functioning in this context.

\subsection{The Sample}

The research was carried out during the second semester of the 2015 and 2016 academic year in 18 bilingual secondary schools in the Madrid Autonomous Community. Two classes in each school participated. We handed the students the questionnaires, then, we interviewed them on another day. All the students were asked the same questions and they were also allowed to speak freely.

The sample consists of 754 students attending grade two of Secondary Education. They belong to the bilingual sections of the three types of bilingual schools: six public, six charter, and six private from both urban and rural areas, which were chosen randomly across the Community of Madrid (cf. Graphs 1 and 2).

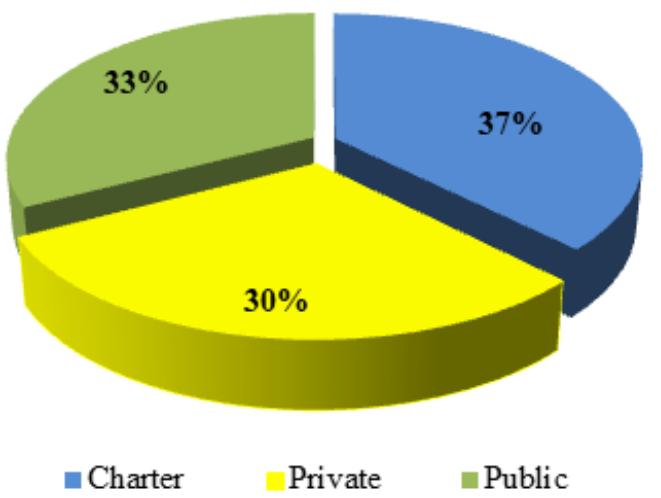

Graph 1. Breakdown of students in relation to type of schools

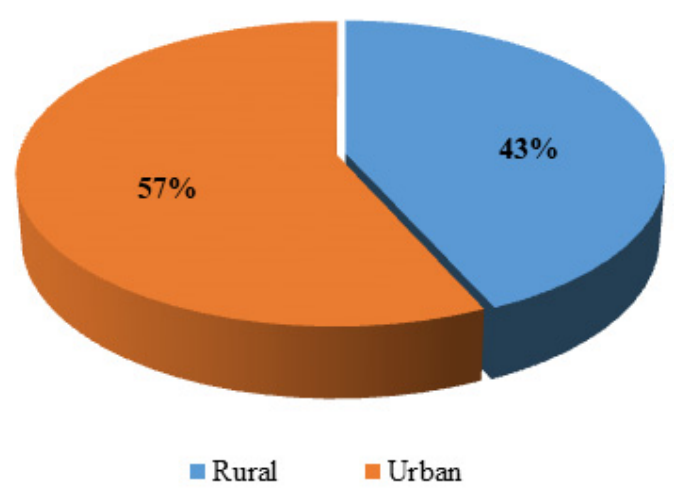

Graph 2. Breakdown of students in relation to school setting

On examining the age of the participants, most of the students sampled range between 13 and 14 years old. $70 \%$ of students are 13 years old, $29 \%$ are 14 years old, and only $1 \%$ is aged 11, 12 or 15 years old (cf. Graph 3).

In relation to gender, there are $53 \%$ of females and $46 \%$ of males. $1 \%$ did not reply to the corresponding item (cf. Graph 4).

In terms of nationality, Spanish (95\%) represents the largest number of participants, then Venezuelan (1\%), and finally other (4\%) (cf. Graph 5). 


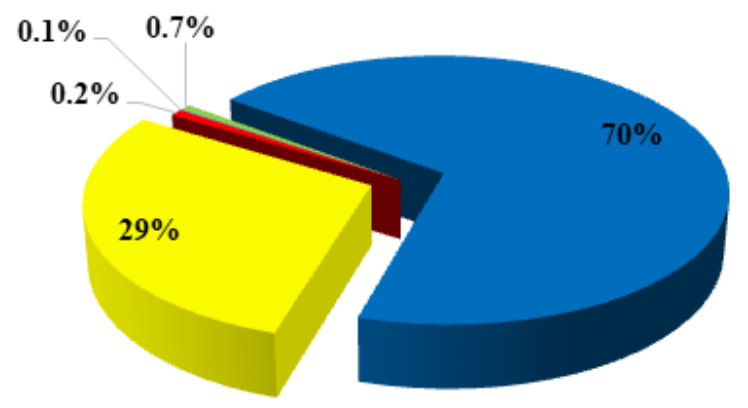

$\square 11=12 \quad \square 13 \quad 14 \quad \square 15$

Graph 3. Age of students

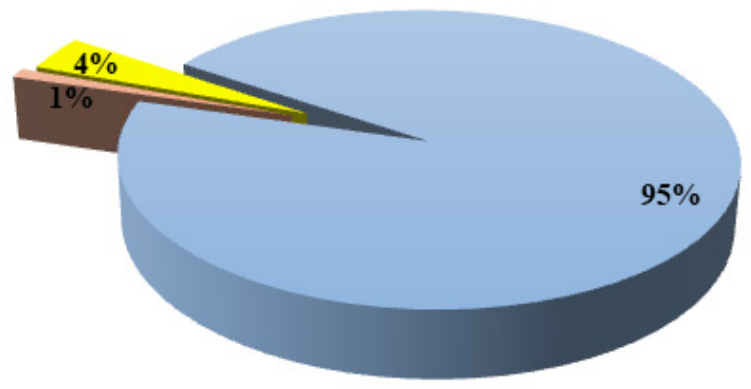

- Spanish $\quad$ Venezuelan Other

Graph 5. Nationality of students

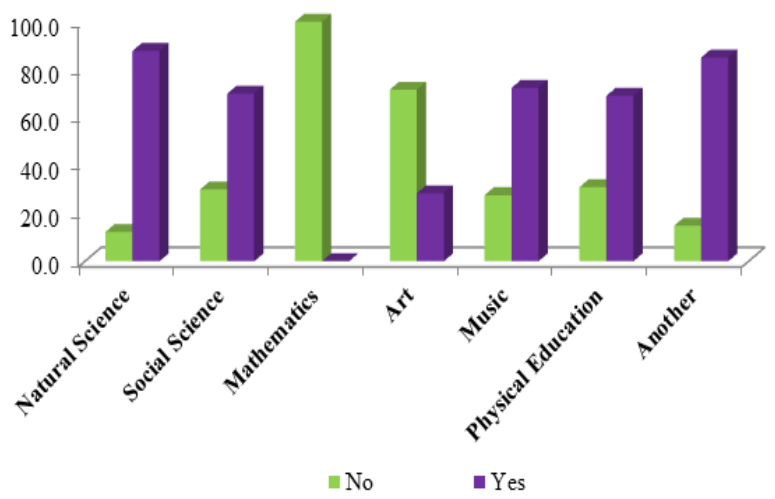

Graph 7. Subjects students take in English

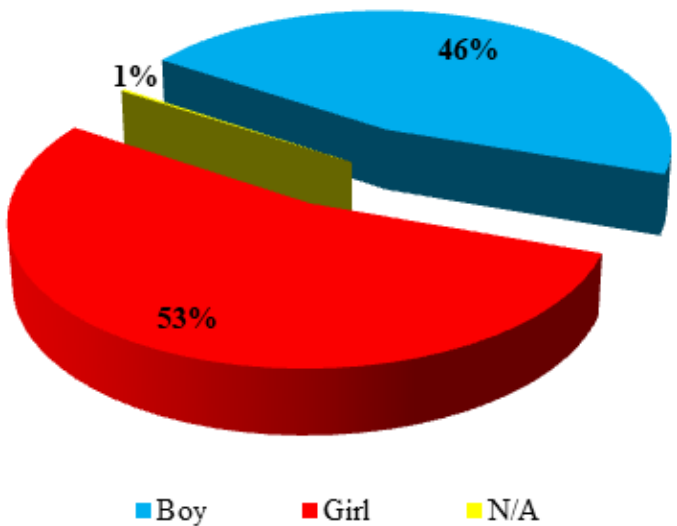

Graph 4. Gender of students

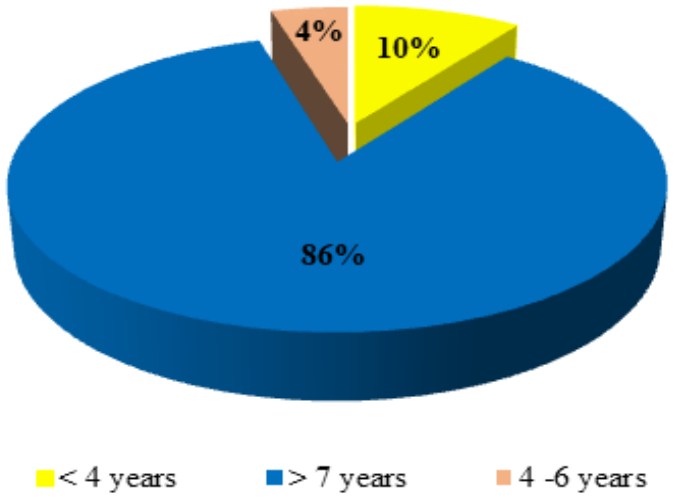

Graph 6. Years of bilingual section experience

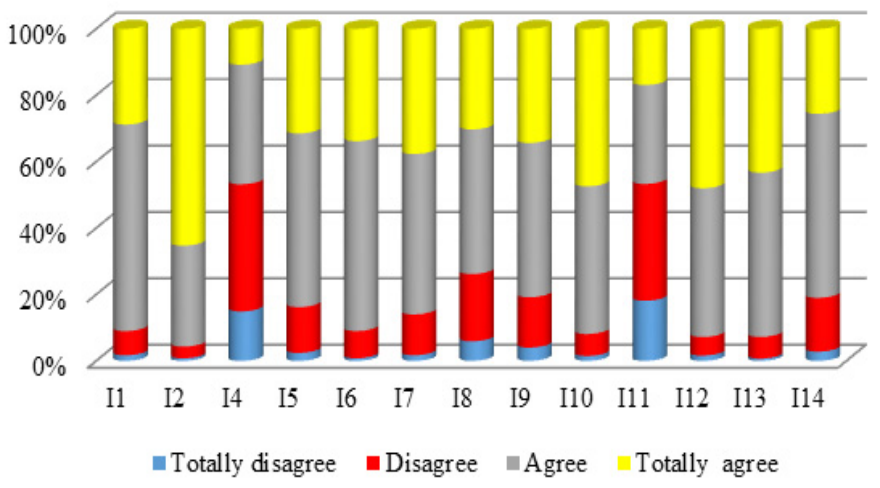

Graph 8. Students' use, competence and development of English in class

On the whole, $86 \%$ of the students who took part in this research have had more than seven years of experience in bilingual education. $10 \%$ of the participants have had less than four years of experience and $4 \%$ have learnt from four to six years in a program of this type (cf. Graph 6).

With respect to the number of subjects taught in English, it varies from one school to another, excluding Math or Spanish, to comply with the regulations of the Consejería de Educación as mentioned above. Of the eighteen schools that were visited, each school has its own policy on how to select which subjects are taught to the students (cf. Graph 7).

As to the exposure of English in the bilingual sections, we do not have enough reliable data to be able to answer this question. The reason behind this is that there are various subjects taught in English and the use of this FL in 
them varied. Fortunately, the question could be answered more accurately in the interview protocol. Also, some classroom observation that we conducted gave us a clear idea about the percentage of English use in general, which is high (between $80 \%$ and $100 \%$ ) by both teachers and students.

\section{Results and Discussion}

In terms of students' use, competence, and development of English in class, the majority of students state that they either agree or strongly agree with all the items, except items 4 and 11, with which, contrarily, a considerable percentage of students disagree; almost half of the students think that their mother tongue (Spanish) has not improved due to their enrolment and their participation in the bilingual program (item 4), and nearly the same percentage (around 50\%) of the students do not welcome the use of more English in the bilingual class (item 11). This finding is supported by Lasagabaster \& Doiz's (2016, p. 12) results. They have documented that "as the younger students progress in their CLIL instruction, the importance they attached to these language aspects decreased slightly, although they were still deemed to be relevant." Students strongly believe that they are developing and improving basic competences in the classroom, and their English has improved. These findings fall in line with other researchers such as Madrid and Hughes (2011) and Lancaster (2016).

Content knowledge and understanding of subjects taught have therefore improved due to their participation in bilingual education (items 1,2, and 5). Learners not only understand how the language works, and the connection between English and Spanish but also, they improved in these concepts (items 6 and 7). They gained confidence because they are participative and enthusiastic within the CLIL stream, and they are interested in the bilingual class (items 8,9 , and 10). Regarding items 12, and 13, the vast majority of students replied that they have highly adequate listening and speaking, as well as adequate reading and writing skills in English. They have a high positive input and output of linguistic level. These results also coincide with Woore's (2015) findings. He found that in Madrid, "students' oral language production - both when answering teachers' questions, and when asking questions of their own - demonstrated an impressive facility with communication and command of the language, in terms of both syntax and lexis" (p. 4). Moreover, they have acquired an adequate knowledge of socio-cultural and intercultural awareness in the target language (item 14) (cf. Graph 8).

In regard to methodology, a high percentage of students strongly agree that teachers develop a new educational methodology based on working in small groups to integrate content and language successfully. In the bilingual class, tasks, projects, and teamwork (items 15, 16 and 18) are highly applicable by CLIL teachers. Simultaneously, students admit that they are learning more vocabulary in the bilingual class (item 17). All these positive findings to a great extent align with other earlier and current studies in some Spanish communities, especially with those by Cabezas Cabello, 2010; Lancaster, 2016; Louise Oxbrow, 2018; Woore, 2015 (cf. Graph 9).

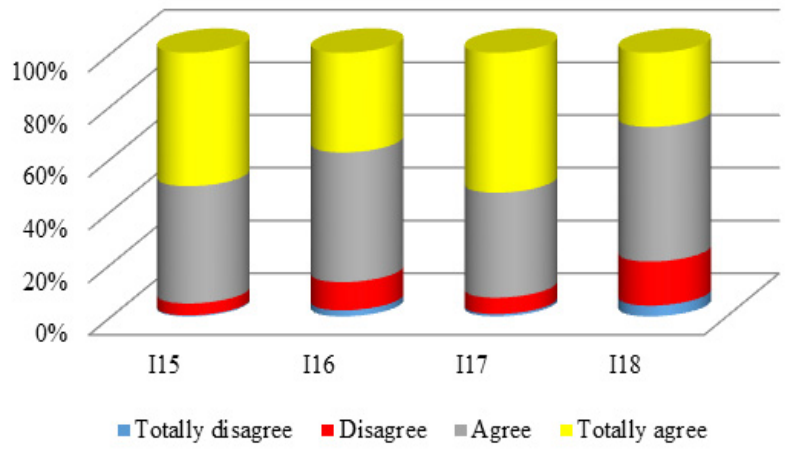

Graph 9. Methodology

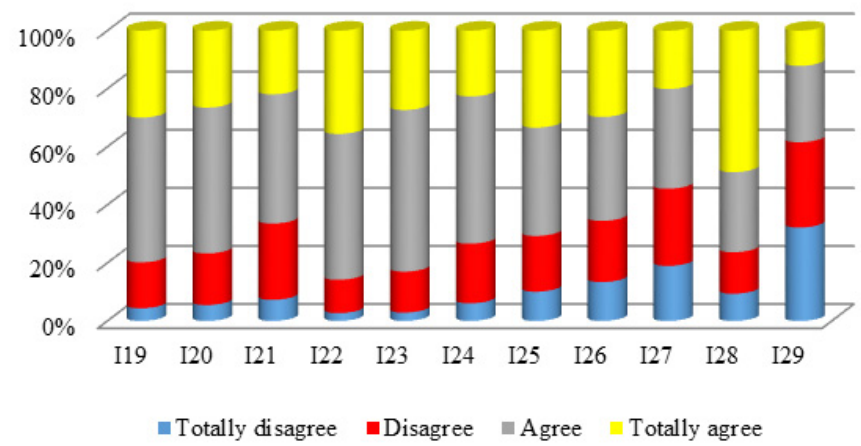

Graph 10. Materials and resources 


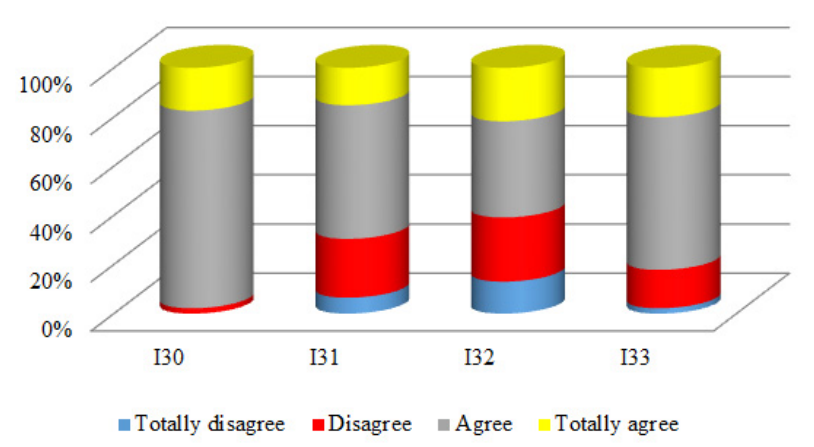

Graph 11. Evaluation

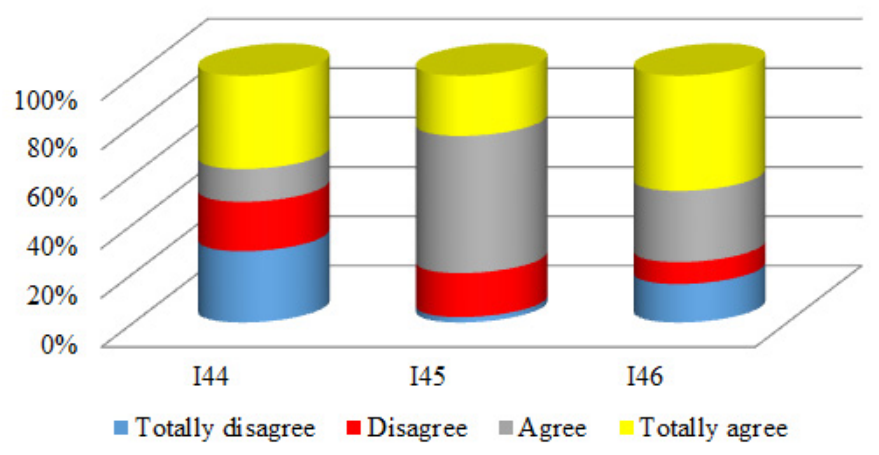

Graph 13. Mobility

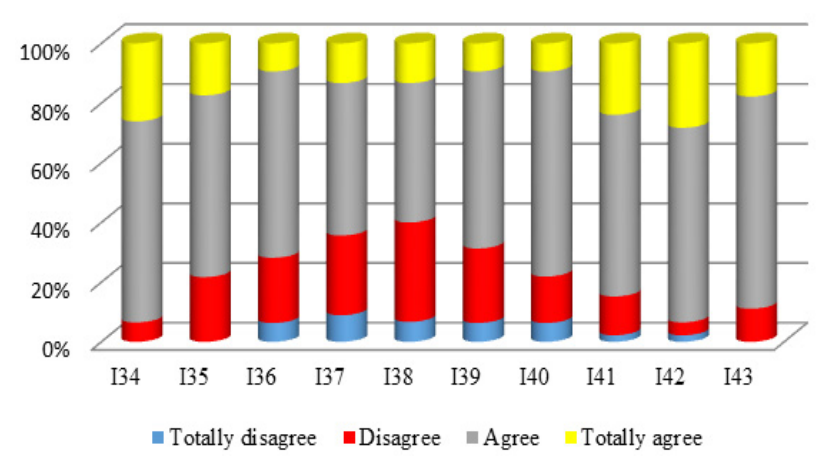

Graph 12. Teachers' use, competence and development of English in class

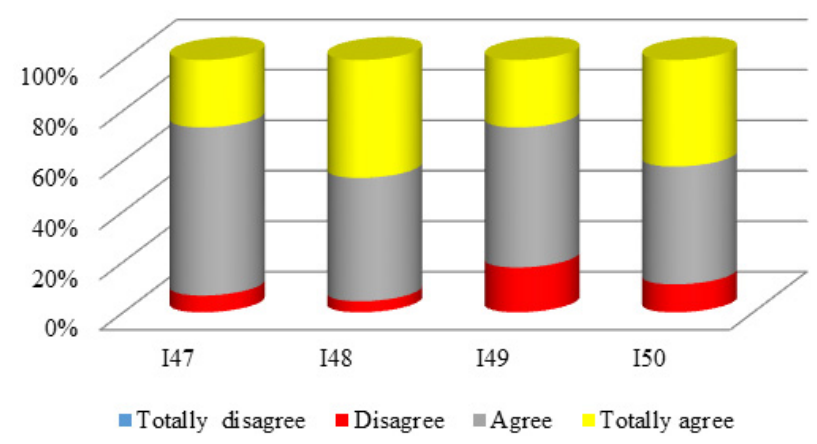

Graph 14. Improvement and motivation towards learning English

Vis-á-vis responses to the items about materials and resources, the data demonstrate that the rich variety of CLIL materials is supporting the process of sharing information, and resources are achieving the main purposes of CLIL. Indeed, the majority of students agree that teachers use and adapt authentic materials (items 19, 20), and a significant percentage of them strongly agree that teaching materials are interesting and innovative (item 21). In fact, more than half of the learners agree that bilingual teachers work in collaboration to deliver the bilingual teaching materials in the class (item 22). Students state that bilingual teaching materials not only encourage them to communicate and interact in English in class (item 23), but also the materials are adapted to cater to all of the student's needs and levels within the class (item 24).

Regarding multimedia educational materials and on-line references, students' opinions vary (items 25 and 26). Blogs, wikis, and webquests are generally used little by half of students (item 27). However, the majority of learners assert that interactive boards are used in class (item 28), and only a third disagree. When commenting on the use of computer-mediated communication (item 29), a high percentage of the participants strongly disagree that this material is used in the classroom. Meanwhile, a third of learners agree or totally agree that they have had opportunities to use and work with this method of communication, such as eTwinning (cf. Graph 10).

Apropos evaluation, research shows that most of the participants agree about the evaluation and assessment process that happens during their learning. Nearly three-quarters of the participants affirm that all bilingual content knowledge learned is evaluated (item 30), and nearly the same amount of learners confirm that bilingual content knowledge in English is prioritized over English competence in evaluation (item 31). Furthermore, students declare that English oral skills are evaluated (item 32), and a large number of them believe strongly that both ongoing and final evaluation are practiced in the classroom (item 33) (cf. Graph 11).

As for teachers' use, competence, and development of English in class, a large percentage (more than 70\%) of students confirm that language teachers, non-linguistic teachers, and teaching assistants are successful in developing their classes (items 34, 35, and 36). Also, most participants hold positive opinions about the role of these three groups of teachers in motivating them, while only a third of students disagree (items 37, 38 and 39 ). These perceptions coincide with those gathered by Lorenzo et al. (2009). 
In item 40, the number of students who agree that teaching assistants work successfully with them in the bilingual class increases. The majority of respondents are in total agreement that their teachers have an adequate language level concerning listening, speaking, reading and writing skills in English (items 41 and 42), together with an adequate knowledge and awareness of the socio-cultural aspects of English (item 43) (cf. Graph 12).

Regarding the mobility block, even though a large number of students have not participated in exchange programs within bilingual modules (item 44), they admit having been encouraged to do so, either by bilingual education teachers or by their families (items 45 and 46) (cf. Graph 13).

Finally, relating to improvement and motivation towards learning English, on the one hand, the vast majority of students are in agreement that taking part in bilingual education does increase the workload of learning (item 47). On the other hand, there are very positive attitudes reported by the students vis-á-vis the remaining items. Nearly all of the participants report that there has been an overall improvement in their English (item 48). In addition, their motivation towards learning it has increased due to their participation in a bilingual program (item 49). These perceptions coincide with research by Gerena and Ramírez-Verdugo (2014) and Lasagabaster and Doiz (2016) with CLIL secondary students in both Madrid and the Basque Country, respectively, as it has shown students' English improvement and high motivation towards learning in a bilingual or a multilingual education class. Finally, the cohort sampled asserted that they have adequate access to English materials outside of school (item 50) (cf. Graph 14).

\section{Conclusion}

The present investigation has allowed us to gather the perceptions that second grade CSE learners have of the CLIL program. The empirical findings obtained from the application of qualitative instruments (questionnaires and interviews) yield very positive student perspectives towards the bilingual sections in the region of Madrid. These results are consistent with those of other research in Madrid, in Spain, and throughout Europe (Dalton-Puffer, 2011; De Graaff et al., 2007; Gerena \& Ramírez-Verdugo, 2014; Lancaster, 2016; Lasagabaster \& Doiz, 2016; Llinares and Dafouz, 2010; Lorenzo et al., 2009; Pérez Cañado, 2011).

After exploring all the data gleaned from the questionnaires and interviews, it can be argued that there is agreement among the majority of the participants about the various issues under investigation. Students' use, competence and improvement of English in a bilingual program is high. Students underline that evaluation is practiced in a correct way, and CLIL methodology is functioning well in the classroom. They also reflect greater confidence, improvement, and achievements to learning both content and English. To some extent this is what Lancaster (2016) highlighted in her research when she stated that "the CAM bilingual project in Madrid has reported an increase in motivation, self-esteem and confidence amongst all stakeholders" (p. 149).

Another major finding is that the study unveils mixed perceptions from students about their improvement of Spanish. This outcome is not enough to claim whether participating in a bilingual program really helps students to improve their mother tongue or not, and whether there is a positive or a negative impact on the students' mother tongue. Research about the effectiveness of CLIL programs, by conducting a series of tests and classroom observation, should complement these mixed student opinions. We are glad to know, at the time of writing this paper, that Pérez Cañado and her team MON-CLIL (see www.monclil.com) are starting to disseminate very positive results in this respect concerning the Spanish regions of Andalusia, Extremadura and the Canary Islands.

Surprisingly, half of the students do not welcome the use of more English in the bilingual classroom. This lack of interest in learning more English might be because students consider themselves to already have a high level of English, and that they already have linguistic accuracy and fluency in learning the FL.

When it comes to bilingual teaching materials and resources, on the one hand, materials that explore various issues and enhance the learning process in the classroom are exploited. They are interesting and suitable to the students' level. On the other hand, despite the existence of the Internet and computers in most schools, quite a significant number of respondents express the clear need for online material and digital equipment. More attention is needed to provide more digital equipment and materials to fit the needs of learning and teaching through CLIL.

Concerning their teachers' use, competence, and development of English in class, the results show that practitioners are successful in giving their bilingual classes and motivate students to follow them. Despite having few opportunities to participate in exchange programs and needing more training, learners acknowledge that their instructors have the adequate receptive and productive skills, as well as socio-cultural knowledge of the English language. 
In relation to their own participation in mobility programs, this can be argued to be sparse. A remarkable rate, i.e., more than half of the sampled cohorts, admitted that there is a lack of opportunities that open doors for exchange programs abroad.

In summary, for almost all students that took part in this research bilingual sections are a success. Having them learn a second language adds great value to both their personal and future professional growth. In light of their views, learning in a CLIL program is very fruitful. Students gain social abilities and become competent, bilingual speakers. They are improving cognitive skills and critical thinking competences too. These skills and improvements will allow them to contribute back to society what it invested on them through education.

\section{Acknowledgements}

We would like to wholeheartedly thank all the eighteen bilingual schools' directors and head teachers who made us so welcome and generously allowed us access to their schools. Undoubtedly, we are also deeply grateful to the teachers and students of those institutions. They kindly gave us some of their time so that questionnaires could be distributed, interviews conducted, discussions held, and classes observed.

\section{References}

Brevik, L. M., \& Moe, E. (2012). Effects of CLIL teaching on language outcomes. In D. Tsagari, \& I. Csépes (Eds). Language testing and evaluation, collaboration in language testing and assessment (pp. 213-227). Frankfurt-am-Main: Peter Lang AG.

Bruton, A. (2013). CLIL: Some of the reasons why... and why not. System, 41, 587-597. https://doi.org/10.1016/j.system.2013.07.001

Cabezas Cabello, J. M. (2010). A SWOT analysis of the Andalusian Plurilingualism Promotion Plan (APPP). In M. L. Pérez Cañado (Ed.), Proceedings of the 23rd GRETA Convention (pp. 83-91). Jaén: Joxman.

Consejería de Educación, Juventud y Deporte. (2015). Order 1317/2015. Retrieved from http://www.madrid.org/wleg/servlet/Servidor?opcion=VerHtml\&nmnorma=8929\&cdestado=P

Coyle, D. (2010). Foreword. In Y. R., de Zarobe, \& D. Lasagabaster, (Eds.), CLIL in Spain: Implementation, results and teacher training (p. viii). Cambridge Scholars Publishing.

Coyle, D., Hood, P., \& Marsh, D. (2010). CLIL: Content and language integrated learning. Cambridge, UK: Cambridge University Press.

Coyle, D. (2012). Content ad language integrated learning: Language using, learning gains. In M. G., Davies, \& A. Taronna, (Eds.), New trends in early foreign language learning: The age factor, CLIL and languages in contact. Bridging research and good practices (pp. 26-33). Newcastle upon Tyne: Cambridge Scholars Publishing.

De Graaff, R., Koopman, G. J., Anikina, Y., \& Westhoff, G. (2007). An observation tool for effective L2 pedagogy in content and language integrated learning (CLIL). The International Journal of Bilingual Education and Bilingualism, 10, 603-624. https://doi.org/10.2167/beb462.0

Durán-Martínez, R., \& Beltrán-Llavador, F. (2016). A regional assessment of bilingual programmes in primary and secondary schools: The teachers' views. Porta Linguarum, 25, 79-92.

Fernández Fontecha, A. (2009). Spanish CLIL: Research and official actions. In Y. Ruiz de Zarobe, \& R. M. Jiménez Catalán (Eds.), Content and language integrated learning. Evidence from research in Europe (pp. 3-21). Bristol: Multilingual Matters. https://doi.org/10.1080/14636200903400215

Fernández, R., \& Halbach, A. (2011). Analysing the situation of teachers in the Madrid bilingual project after four years of implementation. In Y. Ruiz de Zarobe, J. Sierra, \& F. Gallardo del Puerto (Eds.), Content and foreign language integrated learning (pp. 241-270). Bern, Switzerland: Peter Lang.

Field, F. (2011). Bilingualism in the USA: The case of the Chicano-Latino community. Amsterdam, NLD: John Benjamins. https://doi.org/10.1075/sibil.44

Gerena, L., \& Ramírez-Verdugo, M. D. (2014). Analyzing bilingual teaching and learning in Madrid, Spain: A Fulbright scholar collaborative research project. Gist: Education and Learning Research Journal, 8, 118-136. https://doi.org/10.26817/16925777.117

González, J. M. (2008). Encyclopedia of bilingual education. Los Angeles: SAGE Publications, Inc. https://doi.org/10.4135/9781412963985

Hufeisen. B. (2007). Multilingualism (plurilingualism) in Europe and multiple language acquisition. In D. Marsh, 
\& D. Wolff (Eds.), Mehrsprachigkeit in schule und unterricht: Diverse contexts - converging goals: CLIL in Europe (pp. 115- 130). Frankfurt-am-Main, DEU: Peter Lang.

Lancaster, N. (2016). Stakeholder perspectives on CLIL in a monolingual context. English Language Teaching, 9(2), 148-177. https://doi.org/10.5539/elt.v9n2p148

Lasagabaster, D., \& Doiz, A. (2016). CLIL students' perceptions of their language learning process: Delving into self-perceived improvement and instructional preferences. Language Awareness, 1-17. https://doi.org/10.1080/09658416.2015.1122019

Llinares, A., \& Dafouz, E. (2010). Content and language integrated language programmes in the Madrid region: Overview and research findings. In D. Lasagabaster, \& Y. Ruiz de Zarobe (Eds.), CLIL in Spain: Implementation, results and teacher training (pp. 95-113). Newcastle upon Tyne: Cambridge Scholars Publishing.

Lorenzo, F., Casal, S., \& Moore, P. (2009). The effects of content and language integrated learning in European education: Key findings from the Andalusian bilingual sections evaluation project. Applied Linguistics, 31(3), 418-442. https://doi.org/10.1093/applin/amp041

Lorenzo Bergillos, F., Casal Madinabeitia, S., De Alba Quiñones, V., \& Moore, P. (2007). Introduction. RESLA, $1,11-13$.

Louise Oxbrow, G. (2018). Students' perspectives on CLIL programme development: A quantitative analysis. Porta Linguarum, 29, 137-158.

Madrid, D., \& Hughes, S. (2011). Introduction to bilingual and plurilingual education. In D. Madrid, \& S. Hughes (Eds.), Studies in bilingual education (pp. 17-50). Frankfurt-am-Main: Peter Lang.

Obiakor, F. E., Bakken, J. P., \& Rotatori, A. F. (2010). Current issues and trends in special education: Research, technology, and teacher preparation. Bingley, UK: Emerald Group Publishing. https://doi.org/10.1108/S0270-4013(2010)19

Pavón Vázquez, V., \& Gaustad, M. (2013). Designing bilingual programmes for higher education in Spain: Organisational, curricular and methodological decisions. International CLIL Research Journal, 2(1), 82-94.

Pérez Cañado, M. L. (2011). The effects of CLIL within the APPP: Lessons learned and ways forward. In R. CRESPO, \& M. GARCÍA DE SOLA (Eds.), Studies in honour of Ángeles Linde López (pp. 389-406). Granada: Universidad de Granada.

Pérez Cañado, M. L. (2016). Evaluating CLIL programmes: Instrument design and validation. Pulso: Revista de Educación, 39, 79-112.

Relaño Pastor, A. M. (2014). The commodification of English in 'Madrid, comunidad bilingue': Insights from the CLIL classroom. Springer Science+Business Media Dordrecht, 14, 131-152.

Ruiz de Zarobe, Y., \& Lasagabaster, D. (2010). The emergence of CLIL in Spain: An educational challenge. In Y. R., De Zarobe, \& D., Lasagabaster (Eds.), CLIL in Spain: Implementation, results and teacher training (pp, ix- xvii). Newcastle upon Tyne, UK: Cambridge Scholars Publishing.

Ruiz Gómez, D. (2015). A practical approach to CLIL in L2 content-based courses: Methodological guidelines for the Andalusian bilingual classroom. In D. Marsh, M. L. Pérez Cañado. \& J. Ráez Padilla (Eds.), CLIL in action: Voices from the classroom (pp. 14-30). Newcastle upon Tyne: Cambridge Scholars Publishing.

Vázquez, B. M. (2015). CLIL in three Spanish monolingual communities: The examples of Extremadura, Madrid and La Rioja. Elia, 15, 135-158. https://doi.org/10.12795/elia.2015.i15.07

Woore, R. (2015). Madrid, a bilingual community: A view from the classroom. A report for EMI Oxford. Retrieved

from http://www.education.ox.ac.uk/wordpress/wp-content/uploads/2014/09/Woore-R.-2015-Madrid-a-BilingualCommunity-a-view-from-the-classroom-unpublished-report.pdf

\section{Copyrights}

Copyright for this article is retained by the author(s), with first publication rights granted to the journal.

This is an open-access article distributed under the terms and conditions of the Creative Commons Attribution license (http://creativecommons.org/licenses/by/4.0/). 